\title{
Seismic Assessment of the Matera Cathedral
}

\author{
E. Ramírez ${ }^{1(\mathbb{\triangle})}$, Paulo B. Lourenço ${ }^{2}$, and Michele D’Amato ${ }^{3}$ \\ ${ }^{1}$ Department of Civil Engineering, University of Minho, Guimarães, Portugal \\ jeramirezc@pucp.pe \\ 2 Department of Civil Engineering, ISISE, University of Minho, \\ Guimarães, Portugal \\ pbl@civil.uminho.pt \\ 3 Department of European and Mediterranean Cultures (Architecture, \\ Environment and Heritage), University of Basilicata, Matera, Italy \\ michele.damata@unibas.it
}

\begin{abstract}
This paper presents the seismic assessment of the Cathedral of Matera, in southern Italy, to determine the capacity of the structure when subjected to earthquakes. This church dates back to the $13^{\text {th }}$ century and is one of the most representative monuments of the Apulian Romanesque architecture. Within the context of the evaluation of the seismic response of the cathedral, modal identification tests were performed in order identify and characterize the main dynamic properties of the structure. The results of these tests were used to develop a representative finite element model, which is able to provide the response to seismic actions. A pushover analysis was performed to characterize the seismic behavior of the structure. The results of the seismic analyses on the cathedral show that its vulnerability is high, being the transversal direction the less stiff and resistant. Elements as the nave and the façade, along with the bell tower, might be the most vulnerable to seismic actions. Additionally, it was observed that components as the trusses of the central nave strongly modify the seismic response and capacity of the structure. Apparently, the structure might not be able to withstand a strong earthquake from the region or might present several damage after one. Hence, it is recommendable to perform further studies about the seismic behavior, especially of the most vulnerable elements.
\end{abstract}

Keywords: Historical structures $\cdot$ Masonry structures $\cdot$ Seismic analysis Pushover analysis $\cdot$ FE modelling

\section{Introduction}

Among the cultural heritage on the world, many monuments, buildings and historical sites are located in areas with high seismic hazard. Probably, earthquakes are one of the main factors that cause the loss of heritage. In order to protect heritage buildings, it is important to perform assessment works that allow to understand their history and discuss the current state of the buildings.

The structural analysis of a historical construction is an important tool to determine its safety level to different actions and conditions, as well as to study the necessity to undertake remedial actions. However, the implementation of a model might face 
challenges regarding the main characteristics of the structure in study such as the geometry and materials. For such cases, the use of non-destructive methodologies might be useful to complement the information obtained by traditional methods.

The development of modern inspection and diagnosis techniques represent an important step on the conservation of historical structures. These methods normally have a non-destructive character and provide valuable information about the materials, morphology and/or structure characteristics. Nonetheless, many of these tests are mainly qualitative, and their results should be carefully interpreted. In the present work, the seismic assessment of the cathedral of Matera, located in a seismic-prone area, using nondestructive techniques and structural analysis is addressed.

\section{Cathedral of Matera}

The Cathedral of Matera named as Cattedrale della Madonna della Bruna $e$ di Sant'Eustachio is located in the south of Italy, in the historical center of Matera. Following the Cristian traditions, the façade is oriented facing the west and the altar faces the east. The main body of the structure has a Latin cross distribution and is composed by three naves. The cross section of the main nave corresponds to a basilica church. A triumphal arch divides the nave with the presbytery and transept. Next to the presbytery, at the back of the cathedral and behind the main altar, the apse is located. The architectural distribution of spaces is presented in Fig. 1.

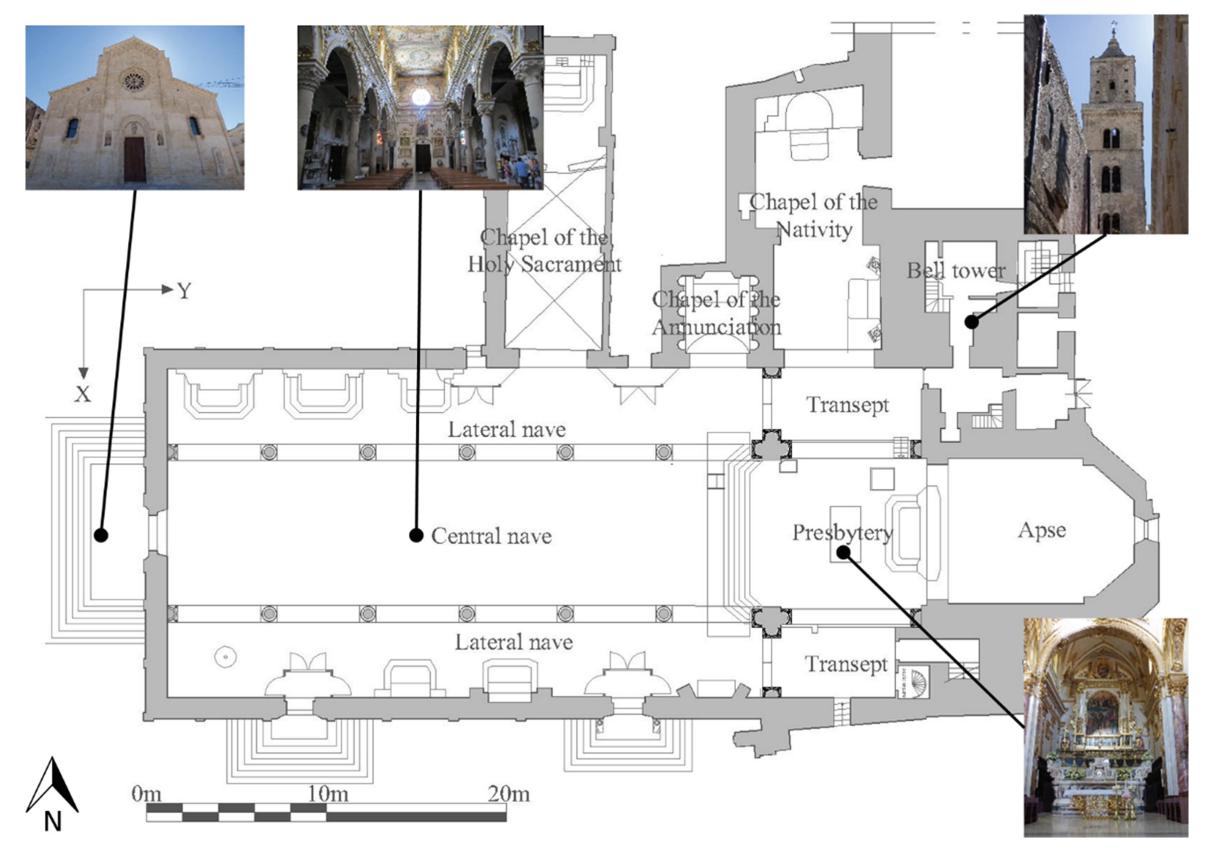

Fig. 1. Plan of Matera cathedral 
It is believed that the construction of the cathedral began between the years 1226 and 1231 [1]. On the access of the bell tower, an inscription indicates that the construction finished on 1270 [2]. However, the chapels were annexed to the north side several years later, between the $15^{\text {th }}$ and $16^{\text {th }}$ centuries [3]. During the $18^{\text {th }}$ century, the choir was completed in 1729 and reconstructed in 1738. Also, it is believed that the dome was reconstructed due to a partial collapse [3]. Regarding the bell tower, two sectors can be distinguished, as it is possible that the upper part, which is different than the rest, was added later [3].

\section{Operational Modal Analysis}

Operation modal analysis (OMA) tests were performed to determine the natural frequencies and modes of the structure. Four piezoelectric accelerometers were placed in different positions of the structure to measure the vibration caused by environmental noise (wind, traffic, etc.) as shown in Fig. 2. The accelerometers used had a sensitivity of $10 \mathrm{~V} / \mathrm{g}$ and their measurement range equals $\pm 0.5 \mathrm{~g}$. Furthermore, a data acquisition system and a portable computer were used to record the signals from the accelerometers. For each arrangement of the accelerometers the signals were recorded during $30 \mathrm{~min}$ with a sampling frequency of $200 \mathrm{~Hz}$.

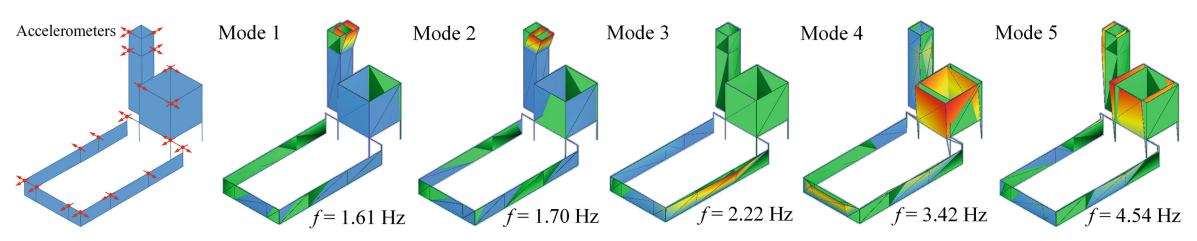

Fig. 2. Natural modes found experimentally

As a first approach, the signals were processed using MATLAB [4] to remove noise from the reading and to determine their quality. After this, using the ARTeMIS Modal software [5], the main dynamic characteristics (natural frequencies and modal shapes) were identified. The technique chosen for this task was the Frequency Domain Decomposition (FDD), which is implemented on the ARTeMIS software.

The first five natural modes and their respective frequencies could be identified. The first $(1.60 \mathrm{~Hz})$ and second $(1.70 \mathrm{~Hz})$ modes are local of the bell tower on the transversal and longitudinal directions, respectively. The third $(2.22 \mathrm{~Hz})$ and fifth $(4.54 \mathrm{~Hz})$ modes are mainly in the transversal direction, while the fourth mode $(3.42 \mathrm{~Hz})$ corresponds to a longitudinal mode. The modal shapes of the five modes found are shown in Fig. 2. 


\section{Numerical Model and Calibration}

\subsection{Model Definition}

Most of the building was considered in the model, except for the chapel of the Holy Sacrament that was not modelled. For simplification purposes, it was assumed that the interaction between the foundation and the structure was ideal, hence translations at the base of the structure were restricted in all the directions. The adjacent structures were modeled as uniaxial springs representing the stiffness of the walls. The roofing system was simplified and only the trusses of the central and lateral naves were modelled.

Given that the walls have considerable thickness in most of the cases (more than $1.00 \mathrm{~m}$ ), these elements were modelled as volume elements. For this purpose, isoparametric tetrahedron solids (TE12L) from the DIANA library [6] were used. On the other hand, the dome and roof over the apse were represented as shell elements due to their smaller thicknesses $(0.20 \mathrm{~m}$ and $0.50 \mathrm{~m}$, respectively), in this case three-node triangular curved shell $(\mathrm{T} 15 \mathrm{SH})$ elements were used. The trusses located on the central and lateral nave were represented as beams using L13BE elements.

\subsection{Calibration of the Model}

In order to calibrate the model, an eigenvalue analysis was carried out to determine the natural frequencies and modal shapes of the numerical model. Given that the results from numerical model are highly sensitive to the boundary conditions and material properties [7] it is necessary to optimize the model to improve the correlation between experimental and numerical results by modifying selected parameters [8]. To evaluate the magnitude of the correlation, the Modal Assurance Criterion (MAC) [9] was used, which is defined as Eq. (1):

$$
M A C_{u, d}=\frac{\left|\left(\varphi_{i}^{u}\right)^{T}\left(\varphi_{i}^{d}\right)\right|^{2}}{\left(\varphi_{i}^{u}\right)^{T}\left(\varphi_{i}^{u}\right)\left(\varphi_{i}^{d}\right)^{T}\left(\varphi_{i}^{d}\right)}
$$

Here, $\varphi_{i}^{u}$ and $\varphi_{i}^{d}$ correspond to the mode shape vector for the experimental and numerical results respectively for the vibration mode $i$. The MAC value can range between 0 and 1 , when this parameter is close to 0 , it indicates that there is no correlation between the experimental and numerical results. However, a value close to 1 (usually larger than 0.7 is assumed as acceptable), means that there is good agreement between the experimental and numerical modes. To optimize the model and obtain the highest MAC values possible, the Douglas-Reid algorithm [10] was used.

In order to optimize the numerical model, 7 parameters were defined. These parameters were chosen after performing a manual calibration stage, in which several factors were evaluated separately. In this stage those variables that did not improved the numerical model were rejected. Finally, within the calibrated properties the Young's modulus and density of the bell tower were considered. Also the Young's modulus of the masonry of the nave was taken into consideration. Finally, interfaces between the tower and nave and longitudinal walls and façade were also calibrated. For each 
property lower, upper and an initial value were defined based on values found in literature (for the Young's modulus and mass of masonry) or on values determined on the sensitivity analysis prior the calibration (interfaces).

\subsection{Updated Model}

The material properties obtained by the optimization process are presented in Table 1 . It can be observed that the Young's modulus of the bell tower masonry has increased considerably, according to [11] this type of masonry could be a cut stone masonry with good bonding. Regarding the interface between the tower and the nave, the results indicate that the normal stiffness is much greater than the transversal stiffness, which might indicate that on the longitudinal direction the connection between the tower and the nave is not very efficient. The values for the normal stiffness between the façade and lateral walls are similar to the normal stiffness between the façade and central walls, indicating that the connection quality between them is similar.

Table 1. Material properties calibrated.

\begin{tabular}{l|l|l|l|l|l}
\hline \multicolumn{2}{l|}{ Property } & Initial & Lower & Upper & Updated \\
\hline \multirow{2}{*}{ Tower } & $\mathrm{E}(\mathrm{GPa})$ & 1.98 & 1.26 & 3.20 & 2.20 \\
\cline { 2 - 6 } & $\delta\left(\mathrm{kg} / \mathrm{m}^{3}\right)$ & 1.60 & 1.40 & 2.20 & 1.40 \\
\hline \multirow{2}{*}{ Nave } & $\mathrm{E}(\mathrm{GPa})$ & 1.26 & 0.60 & 1.90 & 1.00 \\
\hline \multirow{2}{*}{ Int. Tow/Nave } & $\mathrm{DsN}\left(\mathrm{MN} / \mathrm{m}^{3}\right)$ & 333 & 150 & 450 & 344 \\
\cline { 2 - 6 } & $\mathrm{DsS}\left(\mathrm{MN} / \mathrm{m}^{3}\right)$ & 11 & 1 & 45 & 1 \\
\hline Int. Faç/Lat Wall & $\mathrm{DsN}\left(\mathrm{MN} / \mathrm{m}^{3}\right)$ & 140 & 70 & 210 & 134 \\
\hline Int. Faç/Cen Wall & $\mathrm{DsN}\left(\mathrm{MN} / \mathrm{m}^{3}\right)$ & 70 & 35 & 210 & 125 \\
\hline
\end{tabular}

Where $\mathrm{E}$ is Young's modulus, $\delta$ Density, DsN Normal stiffness and, DsS Transversal stiffness.

The final frequencies, modal shapes and MAC values obtained on the calibrated model are presented in Fig. 3. Considering the complexity of the structure and the existing damage in elements as the bell tower, the updated model is considered to be representative. The frequencies of the calibrated model differ from the experimental in no more than $4 \%$ and the MAC values indicate a reasonable agreement between the numerical and experimental modes.

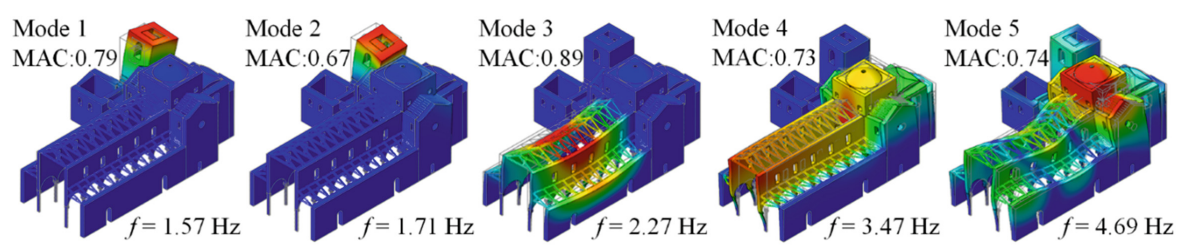

Fig. 3. Modes of the numerical model 


\section{Seismic Assessment}

\subsection{Definition of Nonlinear Properties}

The compressive behavior of the masonry, was represented by a parabolic model, while for the tensile behavior an exponential softening model was used. The constitutive laws mentioned are defined in the material library of the DIANA software [6]. The nonlinear properties were determined based on expressions found in the literature review and the elastic parameters estimated on the calibration of the model.

The compressive strength of the masonry $\left(f_{c}\right)$ was estimated as a fraction of the Young's modulus $E=\alpha f_{c}$, considering a value of $\alpha$ within a range of 200 to 1000, and as proposed by [12], a value of 600 was chosen for $\alpha$. The tensile strength $\left(f_{t}\right)$ was assumed to be a percentage of the compressive strength, and the range between 3 to $10 \%$ proposed by [13] was considered, for the present case the tensile strength was taken as the $5 \%$ of the compressive strength. The compressive fracture energy $\left(\mathrm{G}_{\mathrm{c}}\right)$ was calculated multiplying the compressive strength by a ductility index, which was considered equal to $1.6 \mathrm{~mm}$ [14]. The tensile fracture energy was considered equal to $50 \mathrm{~N} / \mathrm{m}$, similarly to [15]. The nonlinear properties of masonry are summarized in Table 2.

Table 2. Nonlinear properties of masonry

\begin{tabular}{l|l|l|l|l|l}
\hline Material & $\mathrm{E}(\mathrm{GPa})$ & $\mathrm{f}_{\mathrm{c}}(\mathrm{MPa})$ & $\mathrm{G}_{\mathrm{c}}(\mathrm{N} / \mathrm{m})$ & $\mathrm{f}_{\mathrm{t}}(\mathrm{MPa})$ & $\mathrm{G}_{\mathrm{f}}(\mathrm{N} / \mathrm{m})$ \\
\hline Nave masonry & 1.00 & 1.70 & 2700 & 0.08 & 50 \\
\hline Tower masonry & 2.20 & 3.70 & 5900 & 0.18 & 50 \\
\hline Dome masonry & 1.26 & 2.10 & 3400 & 0.11 & 50 \\
\hline Pillars & 4.50 & 7.50 & 12000 & 0.38 & 50 \\
\hline
\end{tabular}

\subsection{Variables Considered}

The assessment of the cathedral to seismic actions was performed using the pushover analysis proportional to the mass in the transversal $(+\mathrm{X})$ and longitudinal $(-\mathrm{Y})$ directions. Given the geometrical configuration of the structure, the positive transversal $(+\mathrm{X})$ and negative longitudinal $(-\mathrm{Y})$, were chosen as the most vulnerable directions. To control the displacements of the structure, four points of the structure were considered, for the transversal direction one on the tower and one on the wall of the central nave and, for the longitudinal one on the tower and one on the façade.

The analysis chosen was applied to two models of the cathedral. The first one (Model A) is the initial model obtained after the calibration and presented in the previous section. The second model (Model B) evaluates the influence of the trusses of the central and lateral naves. In this case, it was assumed that the trusses would be completely disconnect from the structure when the same presents a nonlinear behavior, hence they will not contribute to the global behavior and these elements were not modeled. In Model A, the connection between trusses (beam type elements) and walls (solid type elements) was achieved placing a longitudinal beam on the border of the 
walls were the trusses were supported. This beam was used to avoid concentration of stresses and make the node displacements and rotations (between beams and solids) compatible.

\subsection{Results of the Analysis}

Based on the results of the analyses, the capacity of the structure on the transversal direction $(+\mathrm{X})$ varies from 0.09 to $0.21 \mathrm{~g}$. Regarding the longitudinal direction $(-\mathrm{Y})$, the capacity varies from 0.23 to $0.25 \mathrm{~g}$ (Fig. 4). Compared to the analysis on the transversal direction, the results of the longitudinal direction do not present much variability. Still, the post-peak response is rather different in both models, with a brittle

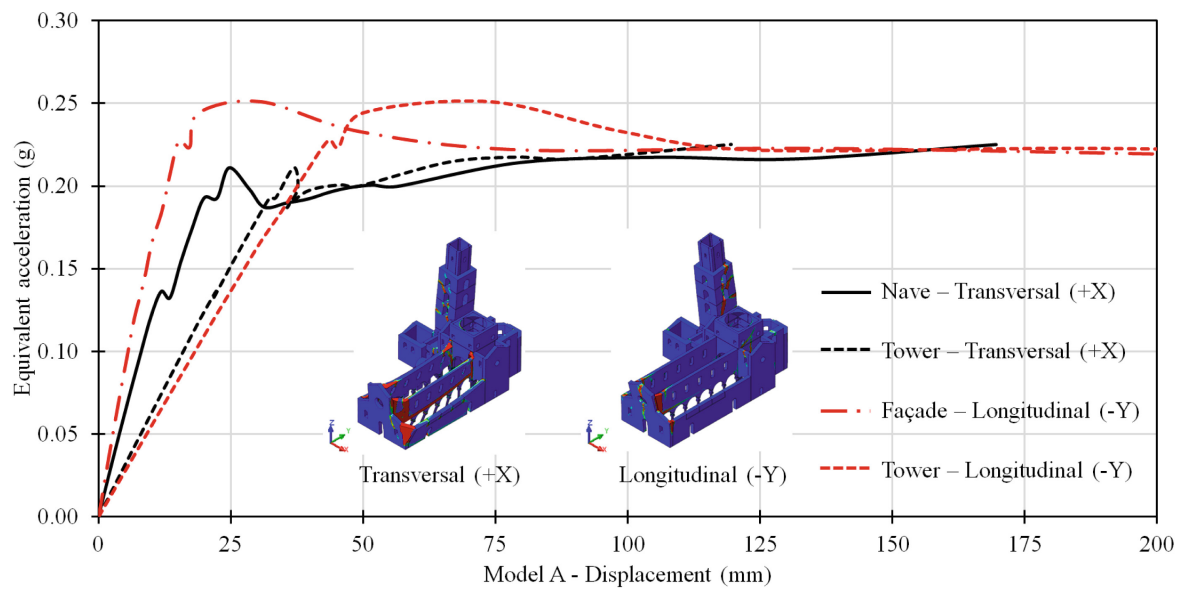

(a)

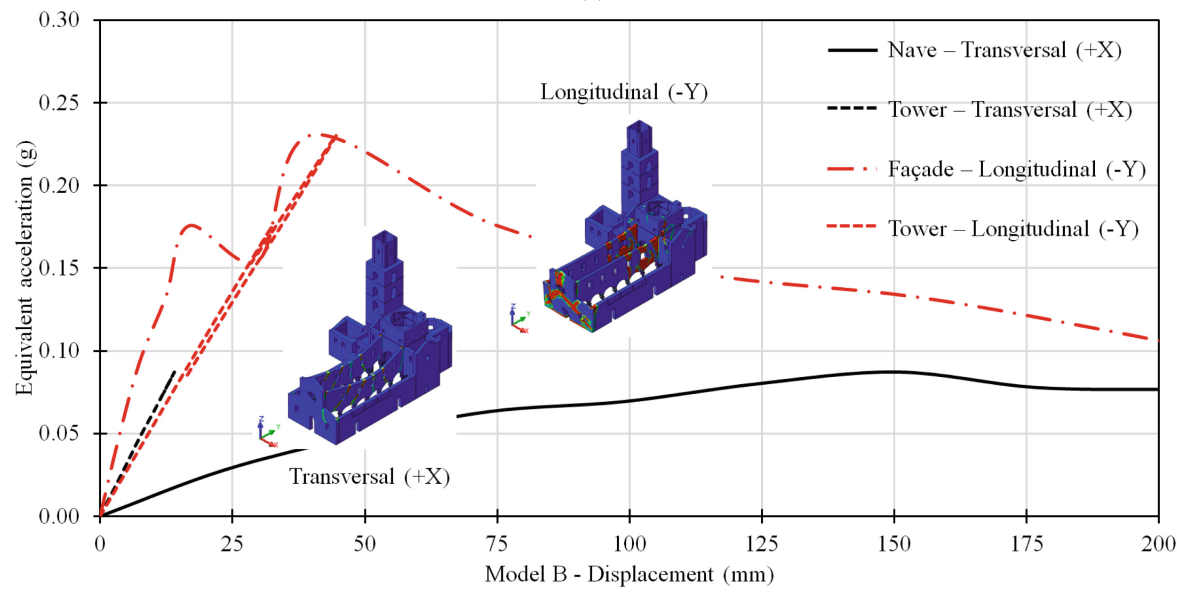

(b)

Fig. 4. Capacity curves and cracking pattern on each model analyzed: (a) Model A and (b) Model B 
behavior on Model B. The analyses indicate that the transversal direction seems to be the most vulnerable.

The trusses have an enormous influence on the response of the structure especially on the transversal direction. The capacity of the structure decreases about $60 \%$ on the transversal direction and also the secant stiffness is reduced. In Model B, only the central nave has a nonlinear behavior and collapses. On the longitudinal direction, the capacity is only reduced about $10 \%$, but the post-peak response is different. Compared to Model A, on Model B the capacity begins to drop rapidly after reaching the peak of the capacity curve.

On the transversal direction the absence of the trusses (Model B) modifies importantly the behavior of the structure. Only the walls of the central nave present a nonlinear behavior, where diagonal cracks due to the out-of-plane displacement of the wall could be observed. On Model A, a failure of the connection between the longitudinal walls and façade was identified, while on Model B the overturning of the central walls was observed. Regarding the longitudinal analysis, in both models the façade presents an out-of-plane behavior during the longitudinal analyses. However, on Model B the walls of the central nave also present a failure mechanism. The cracking pattern of all the models are presented in Fig. 4.

\section{Conclusions}

The results indicate that the implemented Model B (without trusses on the nave) is the most vulnerable, especially on the transversal direction. The inclusion of the timber trusses on the central nave seems to have an important influence on the seismic behavior of the structure. However, these results might represent an extreme case, given that in this case the contribution of these elements to the global stiffness was completely neglected.

For the cases analyzed, the capacity of the structure on the transversal direction ranges from 0.09 to $0.21 \mathrm{~g}$, and for the longitudinal direction from 0.23 to $0.25 \mathrm{~g}$. Comparing this results with the historical data from past events where the maximum acceleration registered was $0.10 \mathrm{~g}$, only the lower limit of the capacity on the transversal direction has a safety factor lower than 1 , for the other cases this factor is higher than 2. However, according to the Italian code, an earthquake with an acceleration of $0.16 \mathrm{~g}$ is expected in the worst of the scenarios. This acceleration surpasses the capacity of Model B on the transversal direction, also the safety factor for Model A is close to 1 , indicating that the structure might exhibit important damage under such an event.

Further studies about the seismic behavior of the cathedral should consider performing a dynamic time-history analysis. This analysis could be especially useful considering that some elements as the bell tower might present an independent behavior from the rest of the cathedral. For this purpose, also the local seismicity must be studied in detail, in order to use a representative input seismic signal from the region. 
Acknowledgements. The authors would like to acknowledge the University of Minho for supporting the experimental campaign. Thanks is also extended to Dr. Nuno Mendes, University of Minho, for his guidance and help for performing the in-situ tests on the cathedral. The authors would also like to thank to the ELARCH project number 552129-EM-1-2014-1-IT-ERASMUS MUNDUS-EMA 21 for funding the graduate studies of the first author.

\section{References}

1. Morelli M (1970) La cattedrale di Matera ha 700 anni. F.lli Montemurro, Matera

2. Calò Mariano MS, Guglielmi Faldi C, Strinati C (2017) La Cattedrale di Matera nel medioevo e nel rinascimento, Prima edizione digitale ed. Editoria Digitale, Matera

3. Ragone A, Ippolito A, Liberatore D, Sorrentino L (2017) Emerging technologies for the seismic assessment of historical churches: the case of the bell tower of the Cathedral of Matera, Southern Italy. In: Handbook of research on emerging technologies for architectural and archaeological heritage, Hershey, PA, USA 17033. IGI Global, pp 159-196

4. Matlab, High-level language and interactive environment for numerical computation. MathWorks, Massachusetts. http://www.mathworks.com/products/matlab

5. SVS (2013) ARTeMIS modal pro user manual. Structural Vibration Solutions, Aalborg

6. DIANA - Finite Element Analysis (2017) User's manual release 10.1. DIANA FEA, Delft

7. Friswell MI, Mottershead JE, Ahmadian H (2001) Finite element model updating using experimental test data: parametrization and regularization. Philos Trans R Soc London A Math Phys Eng Sci 359(1778):169-186

8. Mottershead JE, Friswell MI (1993) Model updating in structural dynamic: a survey. J Sound Vib 167(2):347-375

9. Allemang RJ, Brown DL (1982) A correlation coefficient for modal vector analysis. In: Proceedings of the 1st international modal analysis conference, Orlando

10. Douglas BM, Reid WH (1982) Dynamic tests and system idenfication of bridges. J Struct Div 108

11. CMIT (Circolare del Minitro delle Infrastrutture e dei Trasporti) (2009) Istruzioni per l'applicazione delle "Nuove norme tecniche per le costruzioni" di cui al DM 14 gennaio 2008, Gazzetta Ufficiale della Repubblica Italiana

12. Tomazevic M (1999) Earthquake-resistant design of masonry buildings. Imperial College Press, London

13. Schubert $P$ (1988) The influence of mortar on the strength of masonry. In: Brick and Block Masonry (8th IBMAC), London

14. Angelillo M, Lourenço P, Milani G (2014) Masonry behaviour and modelling. In: Mechanics of Masonry Structures. Springer, Vienna, pp 1-26

15. Ramirez R (2016) Structural analysis of the church of the Monastery of São Miguel de Refojos. Master thesis, University of Minho 